\title{
Guidelines for enhancing learning curiosity of non-formal student using daily life context
}

\author{
Ornwipa Mongkondaw ${ }^{1 a}$, Weerachat Supanyoot ${ }^{2}$ \\ 155/149 Mu.15Rattanatibeth Road Bangbuathong Nontaburi 11110 Thailand \\ ${ }^{2}$ Department of Life Long Education, Facuty of Education, Chulalongkorn University Bangkok \\ 10330, Thailand
}

\begin{abstract}
The purposes of this study were: to study learning curiosity within student, teacher and administrators, and to suggest the student of non-formal education learning curiosity by using daily life context. A sample was selected from a group of student of non-formal education for 400 students, categorized to 184 students of secondary education, students of high school education 216, 40 teachers of non-formal education and 20 administrators with district level of the office of the Non - Formal and Informal Education by Multi - Stage Sampling. The research tools were surveyed by using questionnaire of students. The results of the study were as follows and the questionnaire as learning curiosity of the teacher and administrator from the Non - Formal and Informal Education awareness, and transcribing from focus group discussion. The quantitative analysis by the computer program (SPSS) for statistical analysis and analyzing qualitative data by content analysis were included. The results of the study were as follows a student learning curiosity was in high level, a student supporting for learning curiosity in occupation was in high level, the teacher opinion for learning curiosity of student was in middle level. The supporting should be academic, Work and family consecutive. The administrator of the Non - Formal and Informal Education thought, learning curiosity of student was in middle level. The student should be gained occupation knowledge for the first, because of their lifestyle in the north eastern of Thailand; they needed to support their family. Almost citizens were agriculturist, gardener, farmer or merchandiser, and then to permit academic education, family and socialization, the occupation developing was given precedence.
\end{abstract}

Keywords: Learning curiosity; non-formal student; daily life context.

\section{Introduction}

Concept of sustainable country development based on the sufficiency economy theory

\footnotetext{
${ }^{a}$ Corresponding author: silpafriend@hotmail.com
} 
emphasizes the development of the country and the creation of country immunity in every aspect.

To implementing this concept, the expansion of human potential for utilizing country capital must be support from every sector in the country. All Country Capital, Human Capital, Social Capital, Physical Capital, Financial Capital, Natural Resources and Environmental Capital, and Cultural Capital, shall be integrated and administrated in the same direction for effective result of country development. Of all Country Capitals, Human Capital is the most significant since it is the base for the sustainability of other capitals.

Education is important tool for human development because it will equip human to have needed skill for living called "Analytical thinking". Analytical thinking will make human to achieve ability to select useful information in order to develop their work and also to create knowledge base society. Quality human must have abilities i.e. knowledgeable, consciousness, adaptability, unselfish, learning curiosity both international and domestic, dependent, and creativity (National Education Act 2553 B.E. (2010) Division1, Section7). Learning is not limit to human in childhood and juvenile but it is lifelong.

Human in every age must be fostered the concept of learning curiosity so that they can suitably apply it in daily life context, [5].

The implementation of efficient lifelong learning in Thai population in order to expand education and learning opportunity and also create support activities for learners to be learned with happiness are mission of Office of Non-Formal and Informal Education (ONIE). To mobilize the mission, ONIE recognizes the differentiation between the target learners i.e. learning potential, readiness and individual differentiation, [2]. The efficient learning must response to daily life context since learner will recognize the benefit of learning which made them eagerly to learn. If we would like to gain real utilization from learning, we shall integrate daily life context into learning lesson.

To create learning curiosity in daily life context, everyone should take part in participation, learner must firstly recognize the benefit of learning while family must reinforce by creating positive learning attitude, teacher or administrator must facilitate learner by creating learning curiosity environment, providing variety of teaching technique which is challenging to learner so that learner will focus on the achievement of learning.

Researcher would like to use the concept above as the base for data analyzing in this study.

The study aimed at analyzing learning curiosity environments and its support factors in order to draft guideline for enhancing learning curiosity to non-formal student, teacher and administrator.

\section{Objectives}

To study the perception of learning curiosity on student, teacher and administrator, and present draft guideline for enhancing learning curiosity of non-formal students using daily life context.

\section{Scope of the study}

\subsection{Area scope}

- Non-formal and informal education center in north-eastern of Thailand

- Non-formal and informal education center in district level 


\subsection{Population scope}

- Non-formal student who registered in the basic education core curriculum be. 2551 .

- Instructor who is government employee at non-formal and informal education district center.

- Director of non-formal and informal education district center.

\subsection{Content scope}

This study presents possible guideline for connecting the non-formal and informal education in Thai social context. This draft guideline will help encouraging learning curiosity for non-formal student who reside in the northeastern region of Thailand.

\section{Literature review}

Non-formal education is the education for population in every age. In Thailand, Non-formal Education provides learning in 4 areas; Basic Education, Career Development, Life skill Development and Community and Society Development (Non-Formal and Informal Education Office 2550 B.E. (2007)). Target Population of Non-Formal Education is adult and child who is not register in school system.

Knowles [3] said Adult learning skills is different from child since adult characteristic are Self-Concept, Experience, Readiness to learn and Orientation to learn. For this reason, Non-Formal Education emphasize adult to learn useful knowledge for their daily life in order that they will use the learned knowledge to support their career. Adult learning style encourages learner to learn from experience exchange, to learn with readiness, to learn knowledge from daily life context, to learn for career applying as well as to learn for solving daily life problem.

Learning Curiosity is motivation that people have an eager to learn with full potential; it is a significant skill for ideal people in 21 st century. Learner must be fostered learning curiosity skill into their mindset in order that they can create other needed skills i.e. analytical thinking, self-learning and adaptability [4]. Core of learning curiosity consist of 3 components; 1) Affective 2) Cognitive and 3) Behavior Component, [1].

Behaviors Component which is the evident for the achievement of learning curiosity are the expression of feeling and emotion of learner in daily life context; there are 4 types of learning curiosity behaviors; Learning Curiosity in Family is the behavior that learner look for happiness in family by asking question, learning with opened mind, having learning tools, concentrating on learning, connecting daily life context in learning and recognizing self-potential in learning. Learning Curiosity in Academic is the behavior that learner tries to seek answer for furthering old knowledge with new knowledge in order to develop oneself. Learner is curious to learn, open mind, has learning tools, concentrate on learning, learn by connecting to daily life context and recognize self- potential in learning. Learning Curiosity in Work is the behavior that learner tries to seek answer for suspicious question in order to develop their work. Learner is curious to learn, open mind, has learning tools, concentrate on learning, learn by connecting to daily life context and recognize selfpotential in learning. Learning Curiosity in Social is the behavior that learner tries to seek answer on relationship with other people. Learner is curious to learn, open mind, has learning tools, concentrate on learning, learn by connecting to daily life context and recognize self -potential in learning. 


\section{Methodology}

The study was Survey Research by collecting the information on learning curiosity from students (non-formal program), instructor, and administrator during February to April 2558 B.E.(2015), the details of data collection were shown below;

\subsection{Area scope}

Researcher chose north-eastern of Thailand as sampling area since population in this region has lowest income range and this region also has the most number of students in non-formal education program, however, the rate of graduation is only $20 \%$.

Sampling groups were divided into three groups; 400 students, 40 instructors, and 20 administrators. Researcher chose the Non-Formal and Informal Education District Centers which have the most number of students in each province as a criterion for selecting sample group.

The result of the study divided into two parts, 1) The quantitative analysis of learning curiosity perception in students, instructor, and administrator 2) Guideline for Enhancing Learning Curiosity of Non-Formal Student Using Daily Life Context.

\subsection{Research tools}

This study uses two tools for analysis;

\subsubsection{The testing of Behaviour and Learning Curiosity; this tool consist of 3 parts;}

- The questionnaire for testing the perception of learning curiosity in student, it consists of 59 questions. Respondent has to answer each question by choosing choices, each choices has value which is ranged from 1 to 5 respectively.

-The questionnaire for testing the perception of learning curiosity in instructor and administrator, it consists of question and answer choice same as the student questionnaire, however, there are another part which is open-ended form.

-The open questionnaire asking opinions from student, instructor, and administrator. This tools had been verified by professional and had been validity checked with the 30 students in Nakhon Panom Province. The Behaviours Testing and Learning Curiosity had been verified with Cronbach's Alpha Coefficient at .96 .

\subsubsection{Drafting of Support Guideline for Learning Curiosity}

Researcher synthesized information in no.1 and then drafting Guideline for Enhancing Learning of Non-Formal Student Using Daily Life Context. After that, Focus group meeting with the experts in Lifelong Education and Non-Formal and Informal Education had been arranged in order to consider the draft guideline.

\section{Result}

The Perception of Learning Curiosity in Student: It was found that student had learning curiosity in academic, family, work and social at high level. Learner was opened-mind, recognized self- potential in learning, had knowledge tools and concentrated in learning. The Perception of Learning Curiosity in Instructor : The instructor found that their student had learning curiosity at medium level. However, learning curiosity in academic, family 
and social were at high level. Instructor perceived that learner was opened-mind, recognized self-potential in learning, had knowledge tools and concentrated in learning. The Perception of Learning Curiosity in Administrator: The administrator found that their student had learning curiosity in the medium level. There were behaviours shown that the student had learning curiosity in academic, work and academic. Administrator perceived that learner was opened-mind, recognized self-potential in learning, had knowledge tools and concentrated in learning.

\section{Conclusion and Discussion}

The result found that learning curiosity of the student in Non-Formal and Informal Education of consciousness was at high level, however, the perception of administrator and instructor were different from the learner. Opinion from administrator and instructor on learning curiosity of the student were at medium level. The administrator concluded that learner had outstanding on learning curiosity in work and academic since their behaviours expressed in the form of knowledge curiosity and the connecting of received knowledge to work. Instructor perceived that student was opened-mind, recognized self-potential in learning, had knowledge tools and concentrated in learning.

Guidelines items on supporting learning curiosity for learner, instructor, and administrator had been drafted;

1. Learner Guidelines - Leaner must be reading lover, has responsibility and shall always seeking new knowledge for self-development.

2. Instructor Guidelines - Instructor must be confidence in oneself and has positive attitude. They shall always provide appropriate learning activities to student. Instructor must teach knowledge based on the need of learner, provide activities which stimulate learner to have question, interest in lesson, and provide lesson through real practice.

Here introduce the paper, and put a nomenclature if necessary, in a box with the same font size as the rest of the paper. The paragraphs continue from here and are only separated by headings, subheadings, images and formulae. The section headings are arranged by numbers, bold and $10 \mathrm{pt}$. Here follows further instructions for authors.

3. Administrator Guidelines - Administrator must have positive attitude in determining policy for encouraging learning curiosity in learner. Administrator must "put the right man on the right job"; by selecting instructor into each substance based on their knowledge, ability, and expertise in order that the instructor can create learning curiosity to learner.

\section{Acknowledgements}

The authors gratefully acknowledge Chulalongkorn University for scholarships in support of academic paper presentation in a foreign country.

\section{References}

1. Boonchit Maneechoke, The Relationship between collaborative learning Technique with curiosity behaviour of nursing student. Mahidol University, Bangkok. (1997).

2. Chaiyos Imsuwan, Enhancing lifelong Education Context. Retrieved 17 December $2014 \mathrm{http}: / / 202.143 .137 .105 /$ app0529/Article.htm(2010).

3. Knowles, M. S., The modern practice of adult education: From pedagogy to andragogy. Cambridge: Prentice Hall, (1980). 
4. Ministry of Education, Basic education kaenklang courses. Buddhist 2551(2008). Bangkok: Demonstrations of agricultural cooperative printing of four Thai kanjana. (2009).

5. Sumalee Sungsri, Lifelong learning for Thailand. Nontaburi Sukhothai thammathirat, (2012). 